\title{
RANCANGAN FURNITURE DAN TATA RUANG DENGAN DIMENSI TERBATAS SECARA ERGONOMIS
}

\author{
Lamto Widodo, I Wayan Sukania, dan Rosalia Sugiono \\ Program Studi Teknik Industri Universitas Tarumanagara \\ e-mail: rosaliasugiono@gmail.com
}

\begin{abstract}
ABSTRAK
Pada masa kini, ruang kamar tidak lagi hanya dipakai sebagai ruang istirahat, akan tetapi kini banyak orang yang menghabiskan waktu dan melakukan berbagai aktifitas di dalam ruang kamar. Ruang kamar yang memiliki banyak fasilitas tentunya membutuhkan ukuran dimensi yang besar. Seiring perkembangan waktu, pertambahan jumlah penduduk kota-kota besar di Indonesia terus meningkat. Karena keterbatasan lahan serta harga rumah yang semakin mahal, maka mulai banyak muncul hunian vertical seperti apartemen studio atau rumah-rumah kos. Permasalahan yang dihadapi adalah kamar kos atau ruangan pada apartemen studio memiliki dimensi yang terbatas. Hal ini menyebabkan terbatasnya aktivitas yang dapat dilakukan oleh penghuni ruangan. Berdasarkan permasalahan tersebut, dibutuhkan perancangan ruang yang dilengkapi dengan furniture yang dapat membantu pengguna melaksanakan berbagai aktifitas di area yang sama. Perancangan ruang ini dibuat berdasarkan hasil data kuesioner yang melibatkan sebagian besar pendatang di kota Jakarta yang berada di usia 20-35 tahun dan data Anthropometri orang Indonesia, agar tujuan perancangan ini sesuai dengan kebutuhan konsumen. Banyak hal yang perlu diperhatikan dalam perancangan ruang ini salah satunya adalah ergonomi. Perancangan ini dilakukan dengan menggunakan Autodesk Inventor untuk perancangan ruang dan furniture dan menggunakan analisis RULA pada software CATIA untuk menguji posisi yang ergonomis. Dengan adanya perancangan ruang ini, diharapkan pengguna dapat melaksanakan aktivitas yang dibutuhkan secara efektif
\end{abstract}

Kata Kunci: Ergonomi, RULA, Inventor, Furniture, Ruang Dimensi Terbatas

\section{ABSTRACT}

On these days, bedroom is not only used as a place to have a rest, but many people use it as a place to do their activities. A bedroom which has a lot of facilities of course needs a big sized dimension. As time goes, the number of population on several cities in Indonesia is increase. Due to the lack of spaces in big cities and also the price of housing area that always increase; it creates a lot of vertical residents or studio model apartments and boarding houses. The problem is the space of studio apartment or boarding house room has a limit of dimension. This thing could limit our activities that we can do in the room. Because of this problem, it needs a room design plan that equipped with furniture which can help the user to do many activities on the same place. The room design plan is made from result of data questionnaire which involve most of outsiders in Jakarta on age between 20 35 years old and based of Indonesian anthropometry to make this plan fulfils the customer need. There are a lot of things that should be noticed on this design plan; one of it is about ergonomic. This plan is done by using Autodesk Inventor for room design and furniture and also using RULA analysis from software CATIA to test the most ergonomic position. With this room design plan, customer is expected to do their activities effectively

Keywords: Ergonomic, RULA, Inventor, Furniture, Limited Dimensional Space

\section{PENDAHULUAN}

Pengertian ergonomi banyak didefinisikan oleh banyak tokoh. Dari beberapa definisi tersebut dapat disimpulkan bahwa ergonomi merupakan ilmu yang mempelajari interaksi antar manusia dengan kemampuan dan kapasitas kerjanya, alat kerja, dan lingkungan kerja agar tercipta kondisi yang sesuai diantaranya sehingga tercapai efisiensi dan produktivitas kerja yang maksimal [1].

Anthropometri adalah sekumpulan data numeric yang berhubungan dengan karakteristik fisik tubuh manusia, ukuran, bentuk dan kekuatan serta penerapan dari data 
tersebut untuk penanganan masalah desain. Penerapan data anthropometri ini akan dapat dilakukan jika tersedia nilai mean (rata-rata) dan standar deviasi dari suatu distribusi normal [1].

Autodesk Inventor Professional (AIP) adalah salah satu perangkat lunak (software) jenis Computer Aided Drawing (CAD) yang lebih menekankan pada pemodelan solid untuk proses pembuatan objek prototipe 3D secara visual, simulasi, dan drafting beserta dokumentasi data-datanya [2].

CATIA (Computer Aided Three Dimensional Interactive Application) adalah salah satu software CAD (Computer Aided Design)/CAM (Computer Aided Machining). CATIA mampu membuat analisa ergonomi tubuh manusia dengan dimensi orang yang dapat disesuaikan dengan menggunakan manikin. Ini menjadikan CATIA sebagai software yang menarik untuk dipelajari membuka wawasan seluas luasnya untuk bereksplorasi dalam mengembangkan kemampuan desain dan manufakturnya secara terintegrasi.

Seiring perkembangan waktu, karena semakin banyak jumlah penduduk dan jumlah lahan yang semakin sedikit maka banyak muncul tempat tinggal vertikal seperti apartemen studio. Sebagian besar pendatang di Jakarta adalah pendatang dengan usia 20-35 tahun [3]. Tujuan penelitian ini adalah mengidentifikasi kebutuhan pengguna kamar serta merancang desain ruang kamar dengan dimensi terbatas agar multifungsi, memiliki fasilitas yang lengkap, sesuat kebutuhan konsumen dan ergonomis.

\section{METODE PENELITIAN}

Metodologi penelitian secara keseluruhan dapat dilihat pada Gambar 1 berikut ini:

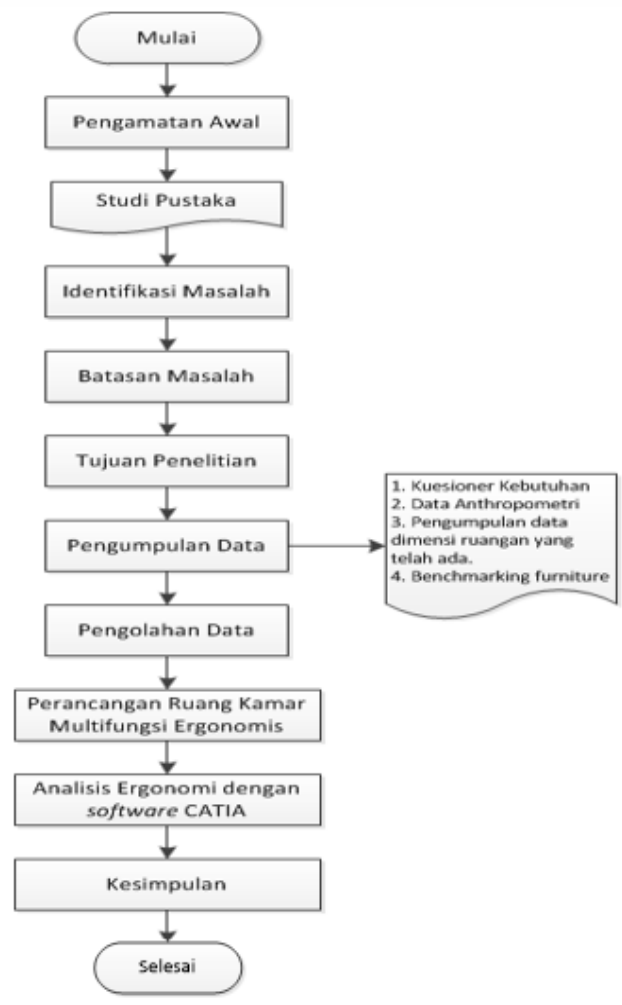

Gambar 1. Metodologi Penelitian

\section{Pengumpulan Data dengan Kuesioner}

HASIL DAN PEMBAHASAN

Perincian sumber data dapat dilihat pada Tabel 1 berikut ini: 
Tabel 1. Tabel Jenis Data Responden

\begin{tabular}{ll}
\hline \multicolumn{1}{c}{ Jenis Data } & \multicolumn{1}{c}{ Data Primer } \\
\hline Alat Pengambilan Data & 40 kuisioner umum \\
\hline \multirow{2}{*}{ Responden } & Warga DKI Jakarta usia 20-35 tahun \\
& Dengan pekerjaan sebagai karyawan, wiraswasta, dan mahasiswa. \\
\hline
\end{tabular}

\section{Identifikasi Kebutuhan Konsumen}

Berdasarkan hasil kuesioner dapat diperoleh kesimpulan bentuk morphologi, serta perhitungan derajat kepentingan setiap aktifitas. Data dapat dilihat pada Tabel 2 dan Tabel 3 berikut ini:

Tabel 2. Tabel Morfologi Kebutuhan Konsumen

\begin{tabular}{lcccl}
\hline \multicolumn{1}{c}{ Uraian } & \multicolumn{4}{c}{ Alternatif } \\
\hline Ukuran kamar & $<9$ m persegi & $9-18 \mathrm{~m}$ persegi & $>18 \mathrm{~m}$ persegi & \\
Jumlah penghuni kamar & 1 Orang & 2 orang & 3 orang & \\
Bahan furniture & Kayu & Plastik & Besi ringan & \\
Warna furniture & Putih & Hitam & Warna kayu & kombinasi \\
\hline
\end{tabular}

Tabel 3. Derajat Kepentingan Kebutuhan Konsumen

\begin{tabular}{|c|c|c|c|c|c|c|c|}
\hline & Peringkat & Bobot & $\begin{array}{l}\text { Jumlah } \\
\text { Pemilih }\end{array}$ & $\begin{array}{c}\text { Jumlah } \\
\text { Bobot }\end{array}$ & Total & $\begin{array}{l}\text { Persentase } \\
\text { kebutuhan }\end{array}$ & $\begin{array}{c}\text { Tingkat } \\
\text { Kepentingan }\end{array}$ \\
\hline \multirow{6}{*}{ Istirahat } & 1 & 6 & 31 & 186 & \multirow{6}{*}{203} & \multirow{6}{*}{$24 \%$} & \multirow[t]{6}{*}{$\begin{array}{llll}1 & 1 & 0 \\
\end{array}$} \\
\hline & 2 & 5 & 1 & 5 & & & \\
\hline & 3 & 4 & 1 & 4 & & & \\
\hline & 4 & 3 & 0 & 0 & & & \\
\hline & 5 & 2 & 1 & 2 & & & \\
\hline & 6 & 1 & 6 & 6 & & & \\
\hline \multirow{6}{*}{ Kerja } & 1 & 6 & 2 & 12 & \multirow{6}{*}{164} & \multirow{6}{*}{$20 \%$} & \multirow{6}{*}{4} \\
\hline & 2 & 5 & 15 & 75 & & & \\
\hline & 3 & 4 & 11 & 44 & & & \\
\hline & 4 & 3 & 9 & 27 & & & \\
\hline & 5 & 2 & 3 & 6 & & & \\
\hline & 6 & 1 & 0 & 0 & & & \\
\hline \multirow{6}{*}{ Bersantai } & 1 & 6 & 1 & 6 & \multirow{6}{*}{152} & \multirow{6}{*}{$18 \%$} & \multirow{6}{*}{4} \\
\hline & 2 & 5 & 12 & 60 & & & \\
\hline & 3 & 4 & 11 & 44 & & & \\
\hline & 4 & 3 & 11 & 33 & & & \\
\hline & 5 & 2 & 4 & 8 & & & \\
\hline & 6 & 1 & 1 & 1 & & & \\
\hline \multirow{6}{*}{ Berkumpul } & 1 & 6 & 1 & 6 & \multirow{6}{*}{115} & \multirow{6}{*}{$14 \%$} & \multirow{6}{*}{3} \\
\hline & 2 & 5 & 3 & 15 & & & \\
\hline & 3 & 4 & 9 & 36 & & & \\
\hline & 4 & 3 & 10 & 30 & & & \\
\hline & 5 & 2 & 11 & 22 & & & \\
\hline & 6 & 1 & 6 & 6 & & & \\
\hline \multirow{6}{*}{ Memasak } & 1 & 6 & 2 & 12 & \multirow{6}{*}{103} & \multirow{6}{*}{$12 \%$} & \multirow{6}{*}{2} \\
\hline & 2 & 5 & 4 & 20 & & & \\
\hline & 3 & 4 & 5 & 20 & & & \\
\hline & 4 & 3 & 6 & 18 & & & \\
\hline & 5 & 2 & 10 & 20 & & & \\
\hline & 6 & 1 & 13 & 13 & & & \\
\hline \multirow{7}{*}{ Merias } & 1 & 6 & 3 & 18 & \multirow{6}{*}{101} & \multirow{6}{*}{12} & \multirow{7}{*}{2} \\
\hline & 2 & 5 & 4 & 20 & & & \\
\hline & 3 & 4 & 3 & 8 & & & \\
\hline & 4 & 3 & 6 & 18 & & & \\
\hline & 5 & 2 & 12 & 24 & & & \\
\hline & 6 & 1 & 13 & 13 & & & \\
\hline & & & & Jumlah & 838 & $100 \%$ & \\
\hline
\end{tabular}


Keterangan Tingkat kepentingan:

$1=<10 \%$

$2=10 \%-13 \%$

$3=14 \%-17 \%$

$4=18 \%-20 \%$

$5=>20 \%$

\section{Penentuan Kebutuhan Teknis}

Hasil kuesioner kemudian diinterpretasikan untuk mendapatkan pernyataan kebutuhan sebagaimana ditunjukkan pada Tabel 4 berikut:

Tabel 4. Interpretasi Pernyataan Konsumen

\begin{tabular}{|c|c|}
\hline Pernyataan Konsumen & Pernyataan kebutuhan \\
\hline Furniture memakan tempat diruangan & $\begin{array}{l}\text { Furniture memiliki fungsi lebih agar penggunaan space } \\
\text { ruangan untuk penempatan furniture lebih efisien }\end{array}$ \\
\hline $\begin{array}{l}\text { Konsumen berada di kamar 6-9 jam dalam } \\
\text { sehari }\end{array}$ & $\begin{array}{l}\text { Ruangan kamar yang memiliki furniture yang cukup untuk } \\
\text { memenuhi kebutuhan konsumen dalam beraktifitas selama } \\
6-9 \text { jam di dalam kamar }\end{array}$ \\
\hline $\begin{array}{l}\text { Kebutuhan membeli furniture berdasarkan } \\
\text { kegunaan }\end{array}$ & Furniture dibuat sesuai dengan kebutuhan konsumen \\
\hline & Keluhan \\
\hline $\begin{array}{l}\text { Disain tempat tidur, lemari pakaian, meja kerja } \\
\text { dan rak perabotan paling memakan tempat }\end{array}$ & $\begin{array}{l}\text { Furniture yang memakan tempat dibuat menjadi kesatuan } \\
\text { furniture yang multifungsi }\end{array}$ \\
\hline Furniture dibuat fungsional & Furniture dibuat dengan berbagai kegunaan (multifungsi) \\
\hline \multirow[b]{2}{*}{ Furniture dibuat ergonomis } & Furniture berdasarkan data anthropometri tubuh manusia \\
\hline & $\begin{array}{l}\text { Peletakan furniture harus disesuaikan dengan keadaan } \\
\text { ruangan agar ruangan tetap memiliki space ruang gerak }\end{array}$ \\
\hline
\end{tabular}

Dari hasil kuesioner didapat tingkat kepentingan kebutuhan konsumen berdasarkan fungsi ruangan yang dibutuhkan. Kemudian dari fungsi kebutuhan tersebut dijabarkan furniture apa saja yang dibutuhkan guna memenuhi kebutuhan fungsi yang diharapkan konsumen. Dapat dilihat pada Tabel 5 dan Tabel 6.

Tabel 5. Tabel Hubungan Antara Kebutuhan dan Furniture yang Dirancang

\begin{tabular}{|l|c|c|c|c|c|c|c|c|}
\hline \multirow{2}{*}{$\begin{array}{c}\text { Kebutuhan } \\
\text { Furniture }\end{array}$} & 1 & 2 & 3 & 4 & 5 & 6 & 7 & 8 \\
\cline { 2 - 9 } & $\begin{array}{c}\text { Tempat } \\
\text { Tidur }\end{array}$ & $\begin{array}{c}\text { Lemari } \\
\text { Pakaian }\end{array}$ & $\begin{array}{c}\text { Meja } \\
\text { Kerja }\end{array}$ & $\begin{array}{c}\text { Rak } \\
\text { Perabot }\end{array}$ & TV & $\begin{array}{c}\text { Rak } \\
\text { buku }\end{array}$ & Kursi/Sofa & Dapu \\
\hline Istirahat & $\mathrm{X}$ & & & & & & $\mathrm{X}$ & \\
\hline Kerja & & & $\mathrm{X}$ & $\mathrm{X}$ & & $\mathrm{X}$ & $\mathrm{X}$ & \\
\hline Bersantai & & & & & $\mathrm{X}$ & & $\mathrm{X}$ & \\
\hline Merkumpul & & & & & $\mathrm{X}$ & & $\mathrm{X}$ & \\
\hline Memasak & & $\mathrm{X}$ & & $\mathrm{X}$ & & & & $\mathrm{X}$ \\
\hline
\end{tabular}

$\mathrm{X}$ : Menunjukkan hubungan yang kuat

$\mathrm{x} \quad$ : Menunjukkan hubungan yang lemah

Tabel 6. Estimasi Nilai Target dari Setiap Kebutuhan

\begin{tabular}{cclc}
\hline No Metrik & Need & \multicolumn{1}{c}{ Metrik } & Kepentingan \\
\hline 1 & 1,7 & Istirahat & 5 \\
2 & $3,4,6,7$ & Kerja & 4 \\
3 & 5,7 & Bersantai & 4 \\
4 & 5,7 & Berkumpul & 3 \\
5 & 4 & Memasak & 2 \\
6 & 2,4 & Merias & 2 \\
\hline
\end{tabular}


Berdasarkan hasil kuesioner, ruangan yang paling banyak ditempati adalah ruang dengan ukuran antara 9-18 meter persegi. Ukuran tersebut biasa digunakan untuk ruang kamar minimalis dengan ukuran minimal 9 meter persegi. Perancangan ini difokuskan kepada area kamar tanpa merancang area memasak. Hal ini dikarenakan area memasak hanya diperuntukkan untuk jenis kamar apartemen dimana ruang memasak menjadi satu bagian dengan ruang istirahat. Sedangkan pada jenis hunian rumah, area memasak berada pada sisi luar ruang kamar. Ruang apartemen tipe studio paling kecil memiliki luas kamar 18 meter persegi. Luas dapur yang ada di dalamnya sendiri hanya berkisar sekitar 4 meter persegi dan sisanya merupakan area untuk konsumen melakukan aktifitasnya. Perancangan dilakukan pada luas kamar 3x3 (9 meter persegi) sebagai luas minimal dari hasil kuesioner supaya furniture yang dirancang dapat menempati luas kamar yang lebih besar dari ukuran tersebut.

Selain itu, pencahayaan dan sirkulasi udara dalam perancangan ini tidak dibahas karena diasumsikan kedua hal tersebut pasti dimiliki suatu ruang kamar. Sirkulasi udara dan pencahayaan dianggap sebagai suatu bagian dari rancang bangunan yang sudah ada. Sirkulasi dalam ruang kamar tersebut dapat dilihat pada Gambar 2.

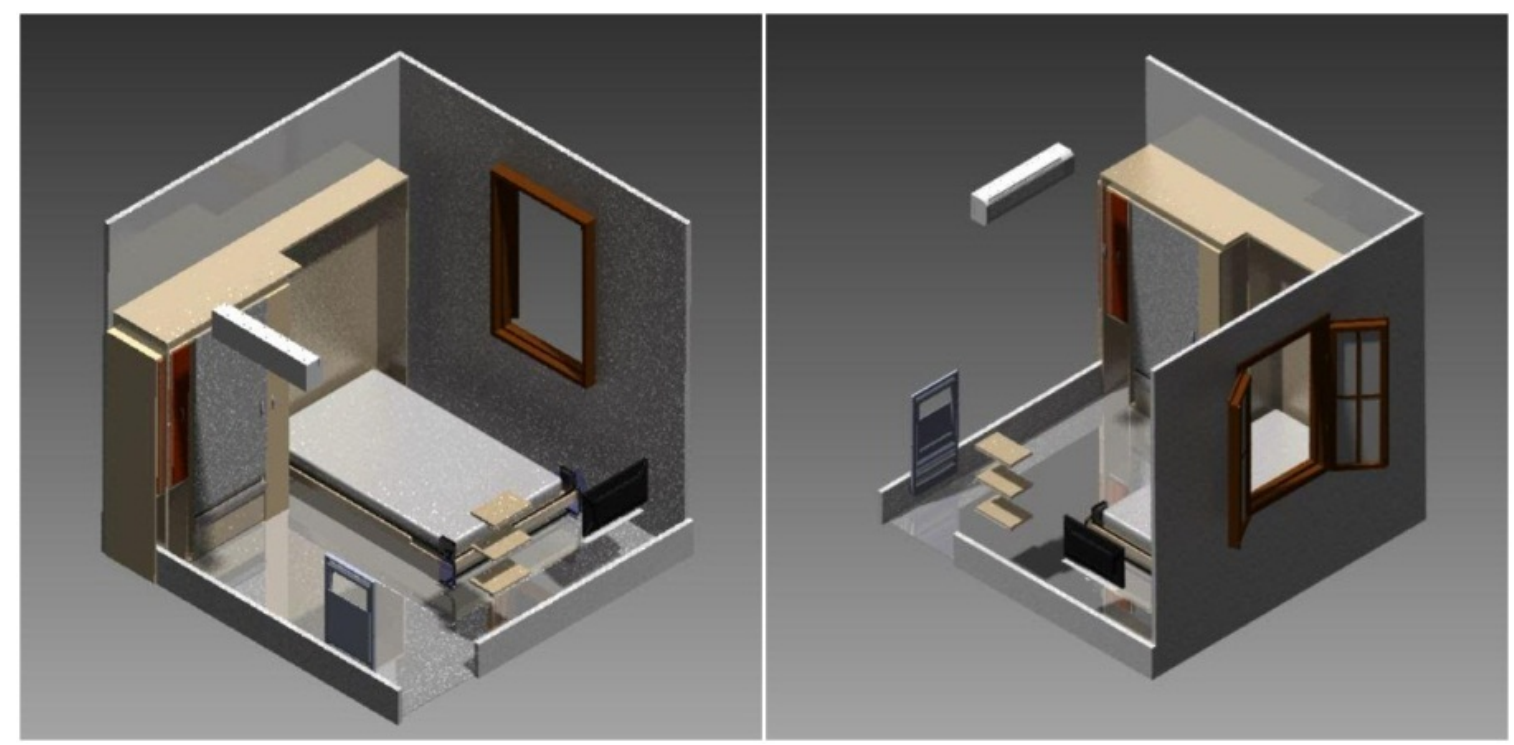

Gambar 2. Sirkulasi Udara dalam Ruangan

\section{Penyusunan Konsep}

Setelah kebutuhan akan fungsi ruangan diketahui, maka selanjutnya kebutuhan tersebut disusun menjadi konsep furniture. Berikut ini merupakan gambar dua alternatif konsep ruangan yang akan dirancang dapat dilihat pada Gambar 3 dan Tabel 7. 


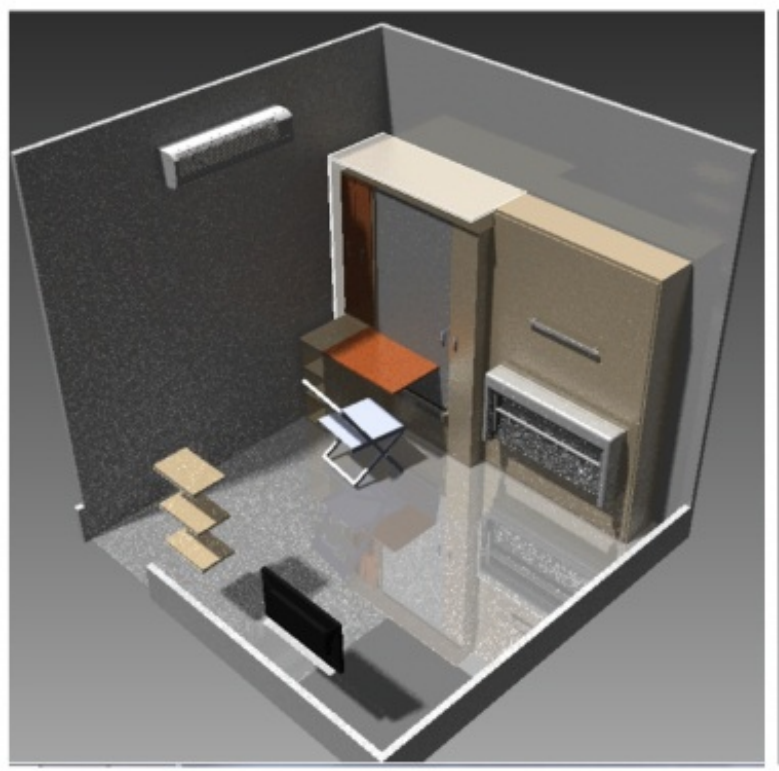

Konsep A Ruangan

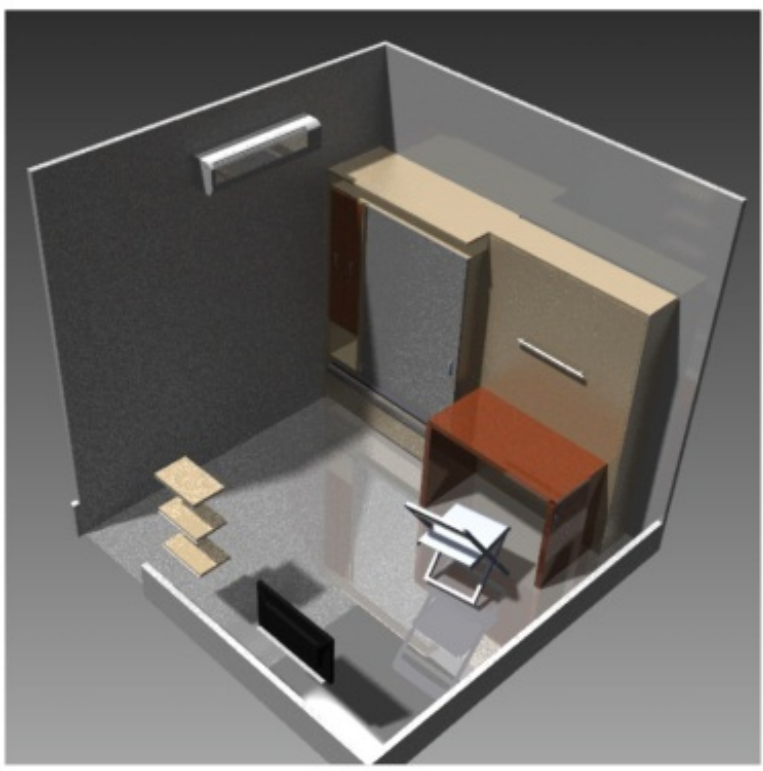

Konsep B Ruangan

Gambar 3. Konsep A dan Konsep B Ruangan dengan Dimensi Terbatas

\begin{tabular}{|c|c|}
\hline Konsep A & Konsep B \\
\hline $\begin{array}{l}\text { Dilengkapi dengan lemari gantung untuk baju pendek } \\
\text { dan untuk baju panjang. }\end{array}$ & $\begin{array}{l}\text { Hanya memiliki lemari gantung untuk baju pendek } \\
\text { tetapi memiliki ukuran lemari yang lebih lebar }\end{array}$ \\
\hline $\begin{array}{l}\text { Meja lipat yang dapat dimasukan ke dalam lemari } \\
\text { utama saat tidak digunakan }\end{array}$ & $\begin{array}{l}\text { Meja lipat yang posisinya menempel pada sisi lemari } \\
\text { tempat tidur yang tertutup }\end{array}$ \\
\hline Sofa menjadi satu bagian pada lemari utama & $\begin{array}{l}\text { Sofa menempel pada sisi lemari tempat tidur yang tertutup } \\
\text { dan dilengkapi oleh busa untuk bersandar. }\end{array}$ \\
\hline
\end{tabular}

Gambar 4. Rancangan Furniture Penyusun Ruang dengan Dimensi Terbatas 


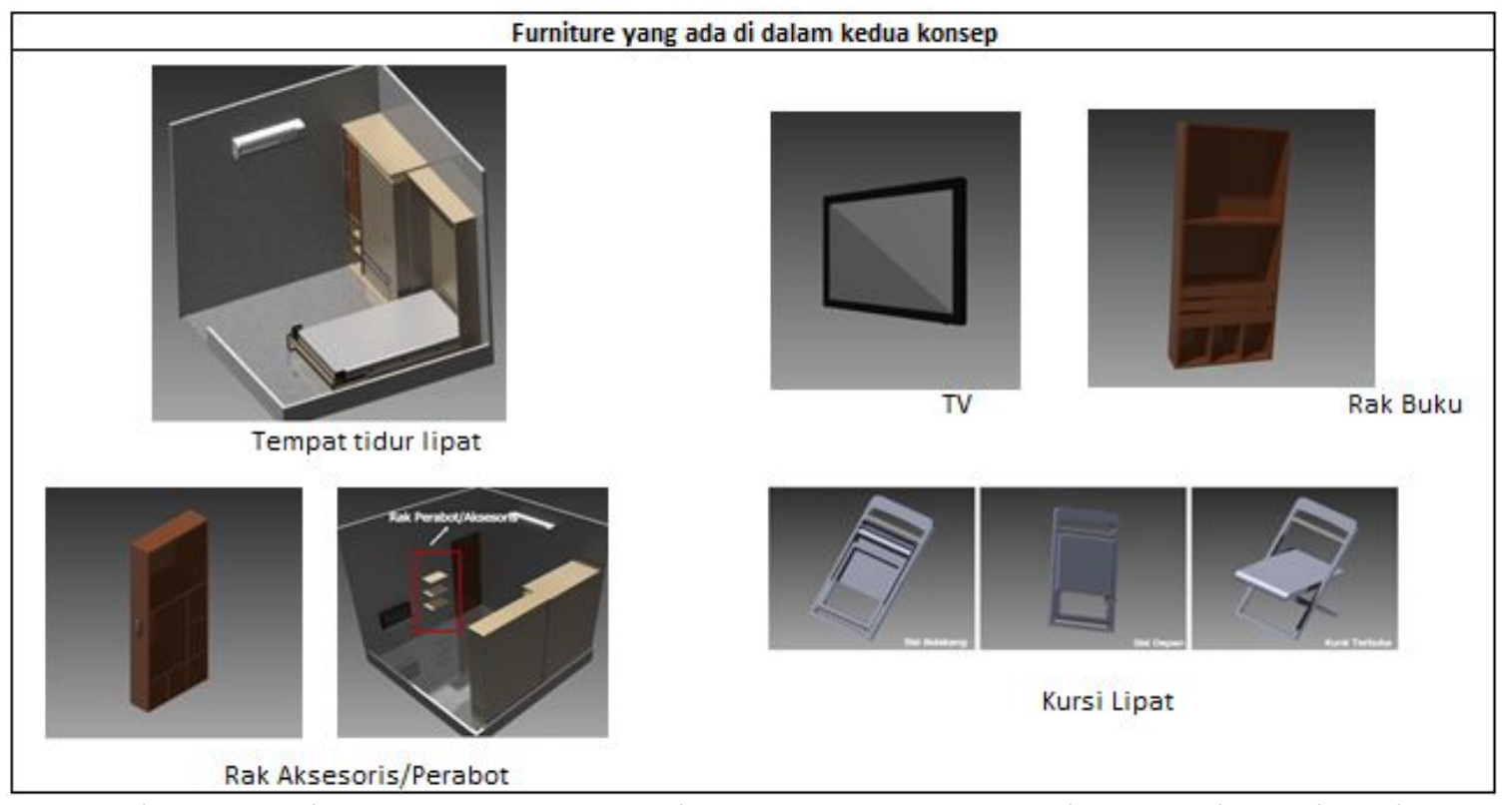

Gambar 4. Lanjutan Rancangan Furniture Penyusun Ruang dengan Dimensi Terbatas

\section{Seleksi Konsep}

Seleksi konsep merupakan proses menilai dengan memperhatikan kebutuhan konsumen serta membandingkan kekuatan dan kelemahan relative dari masing-masing konsep, dan memilih konsep yang terbaik untuk dikembangkan lebih lanjut.

\section{Penyiapan Matriks Seleksi}

Pada matriks ini, berbagai kriteria yang berhubungan disusun untuk masing-masing komponen furniture yang ada di dalam ruangan. Adapun kriteria-kriteria seleksi dengan bobot dapat dilihat pada Tabel 7 sebagai berikut:

Tabel 7. Besarnya Bobot untuk Komponen Furniture

\begin{tabular}{lc}
\hline \multicolumn{1}{c}{ Kriteria Seleksi } & Bobot (\%) \\
\hline Praktis, Fleksibel, dan Compact (tidak makan tempat) & $40 \%$ \\
Kenyamanan Pemakaian (ergonomis) & $20 \%$ \\
Multifungsi & $20 \%$ \\
Desain Menarik & $10 \%$ \\
\hline
\end{tabular}

\section{Menilai dan Meranking}

Tujuan dari menilai dan meranking adalah untuk membandingkan kelebihan dan kekurangan antara alternative konsep yang ada. Dalam menilai kriteria digunakan skala penilaian dari 1-5, pengertian dari skala tersebut dapat dilihat pada Tabel 8.

Tabel 8. Skala Penilaian Konsep [4]

\begin{tabular}{lc}
\hline \multicolumn{1}{c}{ Kinerja Relatif } & Nilai \\
\hline Sangat Buruk & 1 \\
Buruk & 2 \\
Cukup & 3 \\
Baik & 4 \\
Sangat Baik & 5 \\
\hline
\end{tabular}

Nilai bobot yang diberikan untuk masing-masing alternatif diberikan berdasarkan pertimbangan yang berasal dari penilaian berdasarkan literature dan pengamatan yang 
dilakukan oleh diri sendiri. Perhitungan peringkat untuk masing-masing alternatif konsep dapat dilihat pada Tabel 9.

Tabel 9. Penilaian dan Penyelesaian Konsep Ruang Multifungsi dengan Dimensi Terbatas

\begin{tabular}{lccccc}
\hline \multirow{2}{*}{ Kriteria Seleksi } & Bobot (\%) & \multicolumn{4}{c}{ Konsep } \\
\cline { 3 - 6 } & & \multicolumn{3}{c}{ A } & B \\
\cline { 3 - 6 } & & Rating & Nilai Bobot & Rating & Nilai Bobot \\
\hline Praktis, Fleksibel dan Compact (Tidak makan & 40 & 3 & 1,2 & 3 & 1.2 \\
tempat) & 20 & 4 & 0,8 & 2 & 0.4 \\
Multifungsi & 20 & 4 & 0,8 & 3 & 0.6 \\
Kenyamanan Pemakaian (ergonomis) & 10 & 3 & 0,3 & 3 & 0.3 \\
Disain Menarik & Total Nilai & \multicolumn{3}{c}{3,1} \\
\hline & Peringkat & \multicolumn{3}{c}{1} & \multicolumn{2}{c}{ Tidak } \\
\cline { 2 - 6 } & Lanjutkan & \multicolumn{3}{c}{ Ya } \\
\cline { 2 - 6 } & &
\end{tabular}

Analisa Perancangan Produk berikut:

Adapun ukuran furniture penyusun ruangan yang dibutuhkan adalah sebagai

\section{Lebar tempat tidur dan sofa.}

Dimensi lebar lemari, tempat tidur dan sofa ditentukan berdasarkan data anthropometri lebar bahu. Persentil yang digunakan untuk lebar furniture ini adalah persentil 50. Perhitungan lebar furniture menurut data anthropometri adalah sebagai berikut:

Lebar bahu pria persentil $50: 424 \mathrm{~mm}$

Penggunaan tempat tidur dan sofa dapat digunakan oleh dua orang dengan ukuran persentil lebar bahu x $2=424 \mathrm{~mm} \times 2=848 \mathrm{~mm}$

Lebar tempat tidur dan sofa : 1200mm (dengan kelonggaran)

\section{Ketinggian sofa, kursi dan tempat tidur}

Dimensi tinggi sofa dan lemari ditentukan berdasarkan data anthropometri tinggi lipat lutut. Persentil yang digunakan untuk lebar furniture ini adalah persentil 50. Perhitungan ketinggian sofa dan kursi menurut data anthropometri adalah sebagai berikut:

Tinggi lipat lutut pria persentil 50: $403 \mathrm{~mm}$

Ketinggian kursi, sofa dan tempat tidur: $403 \mathrm{~mm}+30 \mathrm{~mm}$ ( sol sepatu $)=433 \mathrm{~mm}$

\section{Lebar tempat duduk (jarak dari lutut ke pantat)}

Dimensi panjang tempat duduk ditentukan dari dimensi jarak dari lipat lutut ke pantat. Data antropometri yang digunakan adalah persentil 95 supaya bisa mengakomodasi semua orang untuk duduk di kursi tersebut:

Jarak dari lipat lutut ke pantat pria persentil $95: 495 \mathrm{~mm}$

Panjang tempat duduk : $500 \mathrm{~mm}$

\section{Ketinggian handle hanger baju}

Dimensi tinggi handle hanger baju ditentukan berdasarkan data anthropometri tinggi bahu. Persentil yang digunakan untuk tinggi handle hanger baju adalah persentil 5.

Perhitungan ketinggian handle hanger baju menurut data anthropometri adalah sebagai

berikut:

Tinggi bahu wanita persentil $5: 1184 \mathrm{~mm}$

$118430 \mathrm{~mm}($ sol sepatu $)=1214 \mathrm{~mm}$ 


\section{Space untuk Gantungan Baju}

Pada perancangan furniture ini, gantungan baju dibagi menjadi dua yakni lemari untuk menggantung baju pendek (contoh: kemeja) dan lemari untuk menggantung baju panjang (dress). Ukuran anthropometri yang digunakan sebagai ukuran baju adalah:

Tinggi bahu pada posisi duduk pria persentil 95: $621 \mathrm{~mm}$ (digunakan untuk ukuran space pada lemari gantungan baju pendek)

Tinggi bahu wanita persentil $95: 1361 \mathrm{~mm}$ ( digunakan untuk ukuran space pada lemari gantungan baju panjang)

\section{Lebar Lemari}

Dimensi lebar lemari baju ditentukan berdasarkan data anthropometri jarak genggaman tangan ke punggung pada posisi tangan ke depan. Persentil yang digunakan untuk lebar lemari adalah persentil 5. Perhitungan lebar lemari menurut data anthropometri adalah sebagai berikut:

Jarak genggaman tangan ke punggung pada posisi tangan ke depan wanita persentil 5: $610 \mathrm{~mm}$

Oleh karena itu lebar lemari harus dibawah ukuran $610 \mathrm{~mm}$ supaya tangan tidak perlu menjangkau secara optimal saat mengambil barang dalam lemari. Pada perancangan ini lebar lemari adalah $500 \mathrm{~mm}$.

\section{Ketinggian meja}

Dimensi ketinggian meja ditentukan dari ketinggian siku saat duduk yakni dengan menjumlahkan tinggi lipat lutut dengan tinggi siku pada posisi duduk. Tujuan menentukan ketinggian meja adalah agar pengguna mempunyai ruang yang cukup pada saat duduk. Persentil yang digunakan adalah persentil 95 pria. Perhitungan tinggi siku pada posisi duduk dengan data antropometri adalah sebagai berikut:

Tinggi siku pria pada posisi duduk persentil 50: $282 \mathrm{~mm}$

Ketinggian meja: $433 \mathrm{~mm}$ (tinggi lipat lutut + sol sepatu $30 \mathrm{~cm})+282 \mathrm{~mm}=715 \mathrm{~mm}$

\section{Daerah sirkulasi antara tempat tidur saat terbuka dengan dinding}

Desain kamar ini memperhatikan space motion yang baik sehingga tidak mengganggu sirkulasi gerak pengguna kamar. Berikut merupakan pembahasan mengenai sirkulasi gerak pengguna kamar dapat dilihat pada Gambar 4.

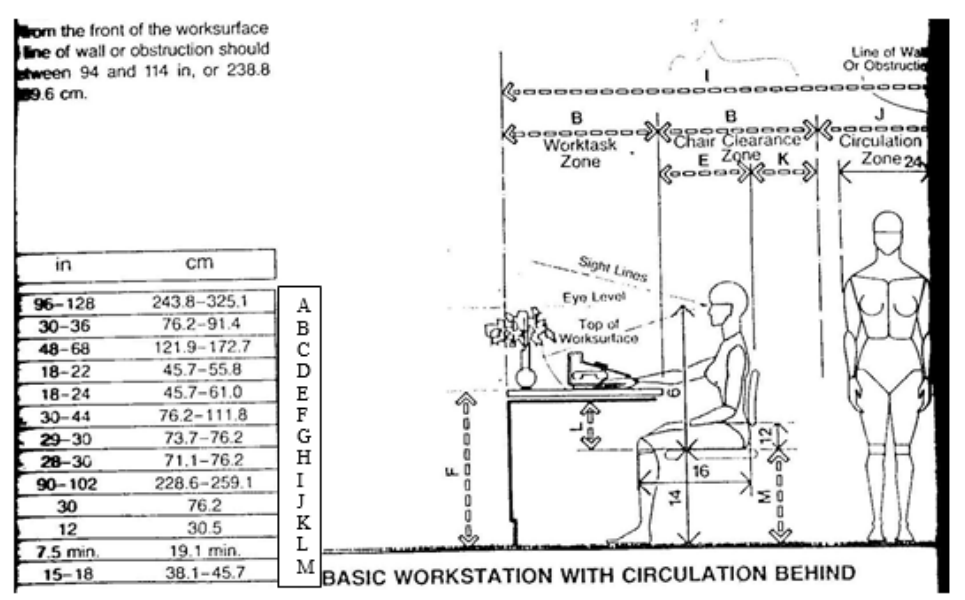

Gambar 5. Sirkulasi Gerak pada Ruangan [5]

Daerah sirkulasi yang sesuai untuk orang Indonesia adalah:

Daerah sirkulasi $=$ kelonggaran+lebar bahu persentil $95=(762-579)+466=649 \mathrm{~mm}$

Jumlah jarak tempat duduk dengan sirkulasi $=762+649=1411 \mathrm{~mm}$

Daerah sirkulasi dapat dilihat pada area J yakni dengan ukuran 76,2 cm [6] [7]. 
Berikut merupakan spesifikasi dari ruangan kamar dengan dimensi terbatas:

1. Ukuran ruangan $3 \times 3$ meter

2. Ruang kamar memiliki furniture yang dapat melengkapi fungsi kebutuhan konsumen akan ruang istirahat, ruang kerja/belajar, ruang berkumpul/bersantai, dan ruang untuk merias yang dapat berganti fungsi secara otomatis.

3. Furniture utama didesain compact menjadi satu kesatuan furniture dan dapat disimpan saat tidak digunakan.

\section{Analisis RULA}

Ruang kamar dengan dimensi terbatas yang telah didesain kemudian dianalisis menggunakan software CATIA. Hasil analisis CATIA dapat dilihat pada Gambar 6 sampai Gambar 11.

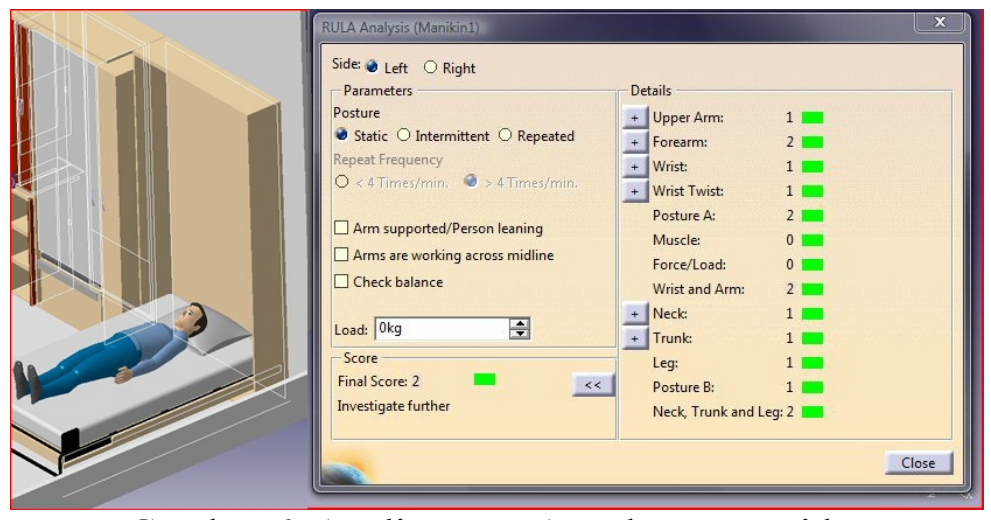

Gambar 6. Analisa RULA pada tempat tidur

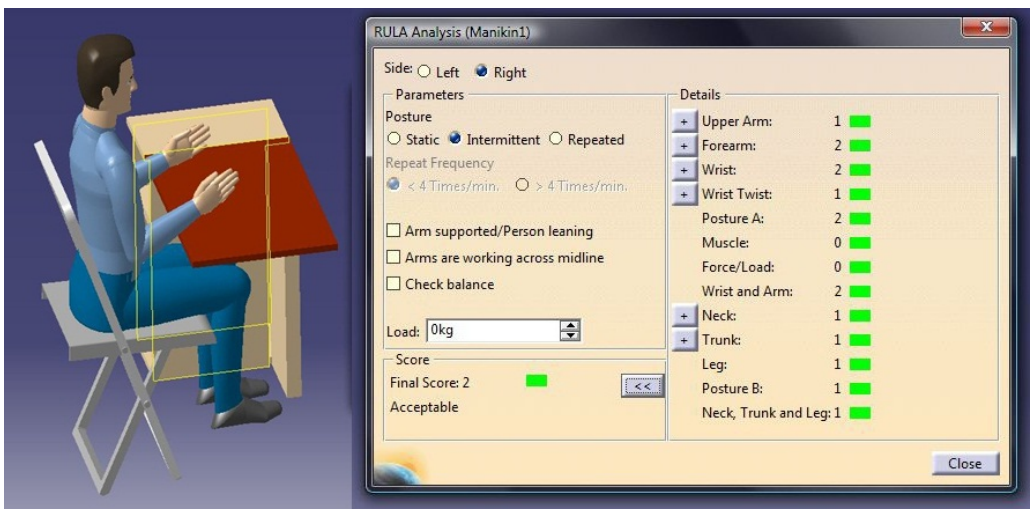

Gambar 7. Analisa RULA pada Meja Kerja

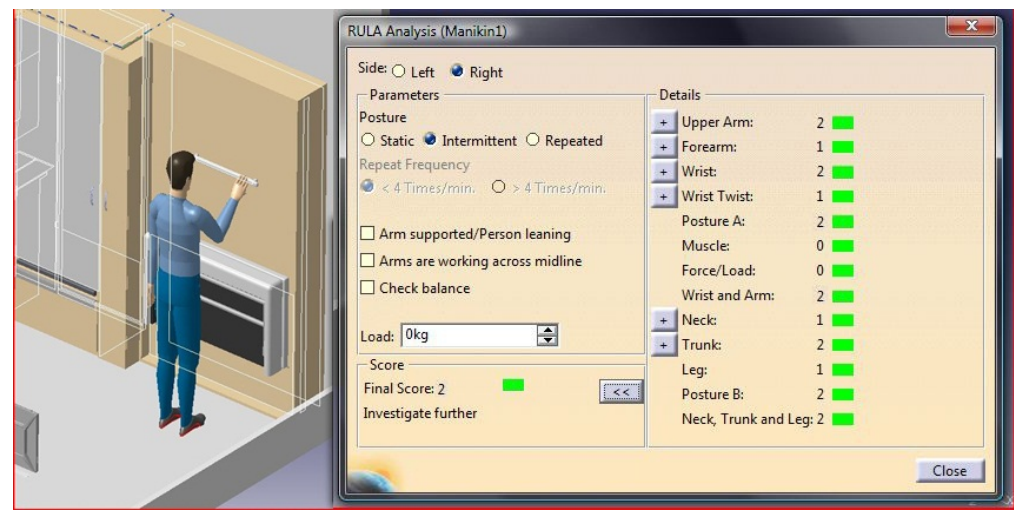

Gambar 8. Analisa RULA Tutup Lemari Tempat Tidur 


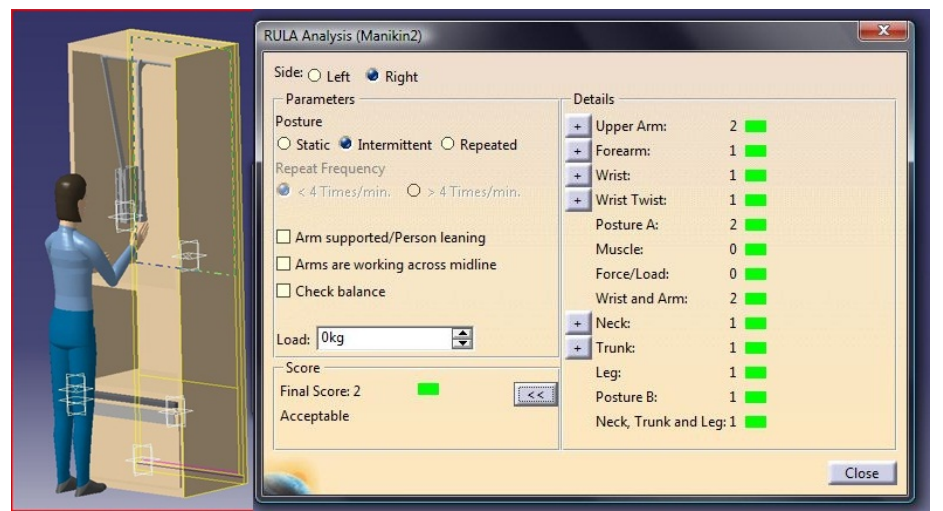

Gambar 8. Analisa RULA pada Handle Gantungan Baju

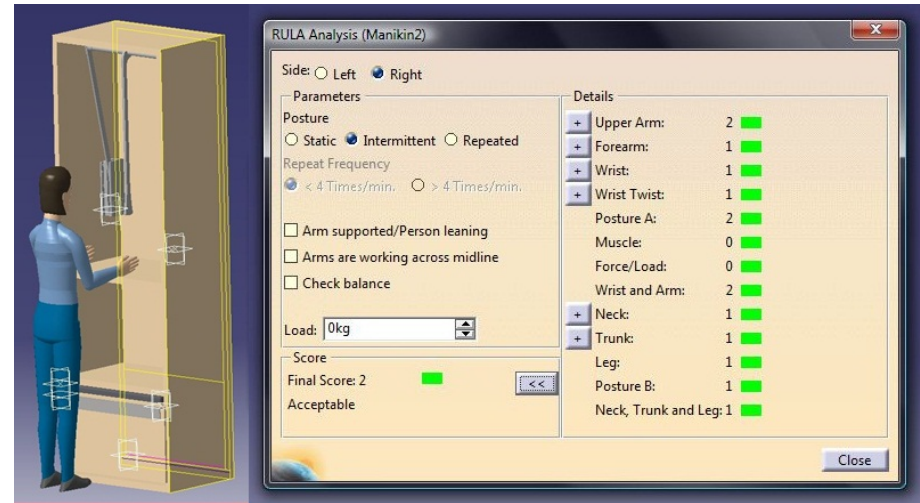

Gambar 9. Analisa RULA pada Rak Lemari

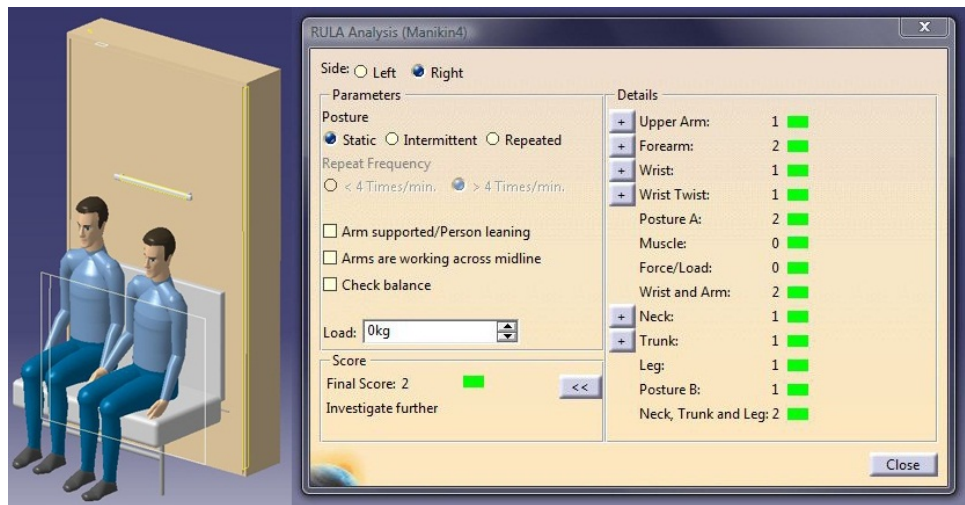

Gambar 10. Analisa RULA pada Tempat Duduk

KESIMPULAN

Kesimpulan yang dapat diambil dari penelitian yang telah dilakukan adalah sebagai berikut ini: yang menjadi responden dalam penelitian ini adalah usia produktiv 20-35 tahun di DKI Jakarta yang memiliki pekerjaan sebagai karyawan, wiraswasta, dan mahasiswa. Ketiga jenis responden tersebut dianggap memiliki kegiatan tetap yang dilakukan di luar ruangan setiap harinya, dan memanfaatkan ruang kamar setelah melakukan pekerjaannya. Fungsi ruang yang dibutuhkan oleh konsumen adalah ruang untuk beristirahat, ruang untuk bekerja/belajar, ruang untuk berkumpul, ruang untuk bersantai dan ruang untuk merias. Furniture yang dirancang merupakan furniture multifungsi yang memenuhi seluruh kebutuhan konsumen akan fungsi ruangan. Furniture di desain dengan bentuk compact, sehingga dapat menghemat space ruangan saat tidak digunakan. Hasil rancangan sudah ergonomis karena hasil final score analisa RULA menunjukkan nilai 2 (dua). 


\section{DAFTAR PUSTAKA}

[1]. Huda, Yon. 2014. Mahir menggunakan Autodesk Inventor Pro 2013. Yogyakarta: Penerbit ANDI

[2]. Nurmianto, Eko. 2008. Ergonomi, Konsep Dasar dan Aplikasinya. Penerbit: Guna Widya.

[3]. McDonald, Peter. Hasil Pendidikan dan Pekerjaan Pendatang Muda ke Jakarta dan Sekitarnya. Jurnal The 2010 Greater Jakarta Transition to Adulthood Survey. 2010

[4]. Juniwaty. Perancangan Ulang Produk Meja Setrika. (Tugas Akhir, Teknik Industri Universitas Atma Jaya Jakarta, 2011)

[5]. Julius Panero, Martin Zelnik. (1979). Human Dimension. Jakarta: Erlangga

[6]. Ismaila, S.O. Journal Anthropometric Design of Furniture For Use in Tertiary Institutions in South-Western Nigeria. Engineering Review,Vo.33,Issue 3,179192.2013

[7]. Wignjosoebroto, Sritomo. 2003. Ergonomi studi gerak dan waktu. Surabaya: Guna Widya

[8]. Santoso, Gempur. Ergonomi, Manusia, Peralatan dan Lingkungan, Prestasi Pustaka, Jakarta, 2004 